\title{
Chronic Caffeine Consumption and the Dexamethasone Suppression Test in Depression
}

\author{
Myung Ae Lee, Pamela Flegel, Oliver G. Cameron, and John F. Greden
}

Received October 31, 1986; revised version received May 26, 1987; accepted June 11, 1987.

\begin{abstract}
Acute caffeine administration increases cortisol and converts the dexamethasone suppression test (DST) to nonsuppression in normal humans; data concerning chronic administration as well as effects in depressed patients are minimal. To determine whether caffeine intake influenced DST results in depression, we retrospectively studied the relationship between regular daily caffeine consumption and pretreatment DST status in major depressives. Daily intake was not correlated with either post-DST cortisol levels or symptom ratings. These data suggest that chronic caffeine use is unlikely to be a major factor in dysregulation of the hypothalamic-pituitary-adrenal axis in depression, perhaps because of the development of tolerance.
\end{abstract}

Key Wurds. Caffeine, dexamethasone suppression test (DST), depression.

Acute caffeine administration increases cortisol in animals (Spindel et al., 1983) and humans (Spindel et al., 1984; Uhde et al., 1984; Charney et al., 1985). Uhde et al. (1985) reported the conversion of dexamethasone suppression test (DST) suppressors to nonsuppressors by giving oral caffeine 1.5 to 2 hours before 4 p.m. post-DST blood sampling in a small sample of depressed patients and normal controls.

Greden et al. (1978) reported that more severely depressed patients used more caffeine, possibly to elevate depressed mood. Therefore, if regular caffeine ingestion also affects the hypothalamic-pituitary-adrenal (HPA) axis in the same way that acute administration does, daily caffeine intake might influence DST findings in depression. However, a study in animals (Spindel et al. 1983) showed that with chronic caffeine administration tolerance developed to caffeine's cortisol-stimulating effect. Also, higher doses of caffeine seemed to be required to stimulate cortisol release (Spindel et al., 1984) than doses that produce behavioral changes (Snyder and Sklar, 1984) or catecholamine release (Robertson et al., 1981) in humans.

An earlier version of this article was presented at the Annual Meeting of the Society of Biological Psychiatry, Washington, DC, May 7-11, 1986.

Myung Ae Lee, M.D., was Fellow, Anxiety Disorders Program; Pamela Flegel, B.S., is Research Associate; Oliver G. Cameron, M.D., Ph.D., is Associate Professor of Psychiatry, Director, Adult Outpatient Psychiatry, and Associate Director, Anxiety Disorders Program; and John F. Greden, M.D., is Professor and Chairman, Department of Psychiatry, University of Michigan, Ann Arbor, M1. Dr. Lee is now at the Cleveland, Ohio, Veteran's Administration Medical Center. (Reprint requests to Dr. O.G. Cameron, Dept. of Psychiatry, University of Michigan Medical Center, 1500 E. Medical Center Dr., Ann Arbor, MI 48109, USA.)

0165-1781/88/\$03.50@1988 Elsevier Scientific Publishers Ireland Ltd. 
Thus, we examined the relationship between pretreatment DST status and retrospective self-report of daily caffeine consumption in a large sample of people with major depression. If chronic caffeine use influences DST status, we might expect higher caffeine use in DST nonsuppressors.

\section{Methods}

One hundred and twenty-one major depressives, defined according to Research Diagnostic Criteria (RDC) (Spitzer et al., 1978) (mean \pm SD age $=40.0 \pm 13.4$ years; range 20-83 years; 42 males; 90 unipolars; 45 inpatients), completed a caffeine questionnaire (Victor et al., 1981) and the State-Trait Anxiety Inventory (Spielberger et al., 1970). Experienced clinicians evaluated all patients with the 17-item version of the Hamilton Rating Scale for Depression (HRSD) (Hamilton, 1960). Anxiety was evaluated because many depressed patients report symptoms of anxiety, and anxiety has been shown to influence caffeine intake (Lee et al., 1985); thus, anxiety might be a relevant factor in interpreting results. The caffeine questionnaire assessed amount of daily caffeine intake from approximately 25 sources, and also inquired about subjective symptom responses to ingesting one cup of coffee, as well as use of other drugs such as minor tranquilizers, antidepressants, hypnotics, and diet pills. Caffeine consumption was determined on the basis of usual daily use outside of the hospital. Although coffee and tea were freely available in the hospital setting, it is possible that caffeine use changed during hospitalization; therefore, inpatients were compared to outpatients (below).

Pretreatment DSTs were done with $1 \mathrm{mg}$ of dexamethasone administered orally at $11 \mathrm{p} . \mathrm{m}$., and blood sampling for plasma cortisol levels at 8 a.m., 4 p.m., or 11 p.m. the next day. At least two blood samples were drawn from each patient; levels of plasma cortisol $>5 \mu \mathrm{g} / \mathrm{dl}$ in at least one sample constituted DST nonsuppression. Plasma cortisol was assayed by the competitive protein binding method (Murphy, 1967); interassay and intra-assay coefficients of variation were $7.2 \%$ and $7.0 \%$, respectively.

Depressives were divided into two groups according to DST outcome (suppressor or nonsuppressor). Caffeine intake was compared across all patients; patients were also divided into three groups on the basis of their caffeine intake: low (0-249 mg/day), moderate (250-749 $\mathrm{mg} /$ day), and high $\geqslant 750 \mathrm{mg} /$ day) (Victor et al., 1981). Possible relationships between caffeine intake with post-DST cortisol levels and symptom severities were examined. Reports of subjective symptom responses to caffeine intake were compared between groups. Because of positive skewness of the distributions, log-transformed values were used for caffeine consumption and post-DST cortisol values. Statistical tests included $X^{2}$, Pearson productmoment correlations, and analyses of variance and covariance.

\section{Results}

Mean ( \pm SD) daily caffeine consumption for all subjects was reported to be $393 \pm$ $415 \mathrm{mg} /$ day (range: 6-2289 mg); $49.6 \%$ were low consumers, $31.4 \%$ were moderate consumers, and $19.0 \%$ were high consumers. There were no significant correlations between caffeine intake and actual cortisol levels at any postdexamethasone time point, either for the total sample or for any of the three caffeine intake groups. There was no significant difference in percentage of subjects in the three caffeine intake groups between DST suppressors $(n=85)$ and nonsuppressors $(n=36)$, whether calculated on the basis of postdexamethasone 4 p.m. level or on the basis of maximum postdexamethasone determination (Table 1). However, after removing by covariance differences in age and depression (HRSD) scores that have been reported to influence caffeine intake (Greden et al., 1978), there was a trend toward increased 
caffeine intake in DST suppressors (adjusted means: $412 \mathrm{mg}$ vs. $349 \mathrm{mg}, p<0.07$ ). There were no differences in use of other drugs between groups. DST suppressors were significantly younger than nonsuppressors (means: 37.9 vs. 47.0 years, $p<0.001$ ).

\section{Table 1. Dexamethasone suppression test (DST) percentages positive and negative at different caffeine intakes}

\begin{tabular}{lccc}
\hline & \multicolumn{3}{c}{ Dally catfelne intake (mg from all sources) } \\
\cline { 2 - 4 } & Low $(<250)$ & Moderate $(250-749)$ & High $(>750)$ \\
\hline DST negative (\%) & $45.9(n-39)$ & $36.5(n-31)$ & $17.6(n-15)$ \\
DST positive (\%) & $61.1(n=22)$ & $16.7(n=6)$ & $22.2(n=8)$ \\
\cline { 2 - 4 } & by $x^{2}$, & $p=0.096$ (highest postdexamethasone cortisol level) \\
DST negative (\%) & $46.0(n=40)$ & $34.5(n=30)$ & $19.5(n=17)$ \\
DST positive (\%) & $62.5(n=20)$ & $18.8(n=6)$ & $18.8(n=6)$ \\
\hline
\end{tabular}

by $x^{2}, \quad p=0.203$ (1600h postdexamethasone cortisol level)

DST suppressors were somewhat less depressed than nonsuppressors, as indicated by the HRSD (means: 18.0 vs. 20.02 ) but somewhat more anxious, as indicated by the trait part of the Spielberger inventory (means: 59.4 vs. 54.0); state anxiety showed no difference. There were no differences in depression or anxiety (state or trait) across the three caffeine intake groups. There were no significant associations between reported daily caffeinc intake and any symptom ratings, cither in the total sample or separately for suppressors and nonsuppressors (see Table 2 for list of symptoms).

In response to ingesting a cup of coffee, $43.3 \%$ of suppressors but only $21.6 \%$ of nonsuppressors reported experiencing anxiety ( $x^{2}$ test, $\left.p<0.02\right)$. Suppressors also reported more of the other symptoms including "lightheadedness" $(p<0.05)$ and "tachycardia" $(p<0.01)$ (Table 2). There were no significant differences in caffeine's mood-elevating ("cheer up," "less depressed," "well being") effect between the two groups (Table 2).

Because all subjects were instructed to rate themselves on the caffeine questionnaire based on an average day outside of the hospital over an unspecified period of time, and caffeine intake might have changed during hospitalization, all inpatients were compared to all outpatients. Inpatients had a higher percentage of nonsuppressors, based on the maximum postdexamethasone level $(42.2 \%$ vs. $22.4 \%$, by $X^{2}$ test, $\left.p<0.03\right)$ or based on the 4 p.m. level $\left(40.9 \%\right.$ vs. $18.7 \%$; by $X^{2}$ test, $p<0.01$ ), and inpatients were significantly older (means: 44.9 vs. 36.8 years, $p<0.001$ ). However there were no differences in caffeine intake or in depression or anxiety scores, and only a small proportion of the symptoms (12\%) differed significantly between the groups.

\section{Discussion}

Daily caffeine intake in major depressives was similar to intake previously reported 
Table 2. Percentages of dexamethasone suppression test (DST) suppressors and nonsuppressors reporting subjective symptoms in response to ingestion of one cup of coffee

\begin{tabular}{lccc}
\hline & $\begin{array}{c}\text { DST } \\
\text { suppressors } \\
(\boldsymbol{n}=\mathbf{8 5})\end{array}$ & $\begin{array}{c}\text { DST } \\
\text { nonsuppressors } \\
(\boldsymbol{n}=\mathbf{3 6 )}\end{array}$ & $\begin{array}{c}\boldsymbol{p} \\
\text { values }\end{array}$ \\
\hline Anxiety & $43.3 \%$ & $21.6 \%$ & $<0.02^{1}$ \\
Diarrhea & 12.2 & 8.1 & $\mathrm{NS}$ \\
Diuresis & 80.0 & 69.4 & $\mathrm{NS}$ \\
Headache & 5.6 & 0.0 & $\mathrm{NS}$ \\
Lightheadedness & 16.7 & 2.7 & $<0.05^{2}$ \\
Palpitation & 18.9 & 10.8 & $\mathrm{NS}$ \\
Stomachache & 15.6 & 18.9 & $\mathrm{NS}$ \\
Spot in front of eye & 2.2 & 2.7 & $\mathrm{NS}$ \\
Tachycardia & 32.2 & 10.8 & $<0.01^{3}$ \\
Tachypnea & 5.6 & 2.7 & $\mathrm{NS}$ \\
Tremulousness & 22.5 & 19.4 & $\mathrm{NS}$ \\
Cheer up & 16.7 & 10.8 & $\mathrm{NS}$ \\
Less depressed & 17.8 & 16.7 & $\mathrm{NS}$ \\
Well-being & 33.7 & 24.3 & $\mathrm{NS}$ \\
\hline
\end{tabular}

1. $x^{2}=5.86$.
2. $x^{2}=5.36$.
3. $x^{2}=7.04$.

in medical (Victor et al., 1981) and psychiatric (Greden et al., 1978) inpatients. Contrary to prediction, on the basis of retrospective reports, DST suppressors tended to use more caffeine than nonsuppressors, but the difference was small. These results suggest that chronic caffeine use produces tolerance to the acute effects of caffeine on the HPA axis, and thus that chronic caffeine use does not strongly influence DST status in depressed patients.

The data collected in this study allowed us also to address the issue of the relationship between anxiety and the DST in depressed individuals. There have been conflicting results in prior studies-either higher anxiety in nonsuppressors, or no difference (Jimerson et al., 1983; Klcin et al., 1984; Sangal et al., 1984; Kocsis ct al., 1985; Roy et al., 1986; Grunhaus et al., 1987), which might be due in part to the use of different instruments to measure anxiety. Our finding of no difference in state anxiety between suppressors and nonsuppressors is consistent with the report of Sangal et al. (1984), who used the same state anxiety measure. The small increase in this study in trait anxiety in suppressors also suggests that there is no substantial difference between suppressors and nonsuppressors. Thus, the results of this study support the view that there is no difference in anxiety between suppressors and nonsuppressors.

Acknowledgment. The research reported was supported, in part, by Public Health Service grants $\mathrm{MH}-28924, \mathrm{MH}-39593$, and $\mathrm{MH}-40216$. 


\section{References}

Charney, D.S., Heninger, G.R., and Jatlow, P.I. Increased anxiogenic effects of caffeine in panic disorders. Archives of General Psychiatry, 42, 233 (1985).

Greden, J.F., Fontaine, P., Lubetsky, M., and Chamberlin, K. Anxiety and depression associated with caffeinism among psychiatric inpatients. American Journal of Psychiatry, 135, 963 (1978).

Grunhaus, L., Flegel, P., Haskett, R.F., and Greden, J.F. Serial dexamethasone suppression tests in simultaneous panic and depressive disorders. Biological Psychiatry, 22, 332 (1987).

Hamilton, M. A rating scale for depression. Journal of Neurology, Neurosurgery, and Psychiatry, 25, 56 (1960).

Jimerson, D.C., Insel, T.R., Reus, V.I., and Kopin, I.J. Increased plasma MHPG in dexamethasone-resistant depressed patients. Archives of General Psychiatry, 40, 173 (1983).

Klein, H.E., Bender, W., Mayr, H., Niederschweiberer, A., and Schmauss, M. The DST and its relationship to psychiatric diagnosis, symptoms and treatment outcome. British Journal of Psychiatry, 145, 591 (1984).

Kocsis, J.H., Davis, J.M., Katz, M.M., Koslow, S.H., Stokes, P.E., Casper, R., and Redmond, D.E., Jr. Depressive behavior and hyperactive adrenocortical function. American Journal of Psychiatry, 142, 1291 (1985).

Lee, M.A., Cameron, O.G., and Greden, J.F. Anxiety and caffeine consumption in people with anxiety disorders. Psychiatry Research, 15, 211 (1985).

Murphy, B.E.P. Some studies of the protein-binding of steroids and their application to the routine micro and ultramicro measurement of various steroids in body fluids by competitive protein-binding radioassay. Journal of Clinical Endocrinology and Metabolism, 27, 973 (1967).

Robertson, D., Wade, D., Workman, R., Woosley, R.L., and Oates, J.A. Tolerance to the humoral and hemodynamic effects of caffeine in man. Journal of Clinical Investigation, 67, IIII (1981).

Roy, A., Jimerson, D.C., and Pickar, D. Plasma MHPG in depressive disorders and relationship to the dexamethasone suppression test. American Journal of Psychiatry, 143, 846 (1986).

Sangal, R., Correa, E.I., and DePaulo, J.R. Depression and anxiety inventories, and the dexamethasone suppression test. Biological Psychiatry, 19, 1207 (1984).

Snyder, S.H., and Sklar, P. Behavioral and molecular actions of caffeine: Focus on adenosine. Journal of Psychiatric Research, 18, 91 (1984).

Spielberger, C.D., Gorsuch, R.L., and Lushene, R.E. State-Trait Anxiety Inventory Manual. Consulting Psychologist Press, Palo Alto, CA (1970).

Spindel, E., Griffith, L., and Wurtman, R.J. Neuroendocrine effects of caffeine: Il. Effects on thyrotropin and corticosterone secretion. Journal of Pharmacology and Experimental Therapeutics, 225, 346 (1983).

Spindel, E.R., Wurtman, R.J., McCall, A., Carr, D.B., Conley, L., Griffith, L., and Arnold, M.A. Neuroendocrine effects of caffeine in normal subjects. Clinical Pharmacology and Therapeutics, 36, 402 (1984).

Spitzer, R.L., Endicott, J., and Robins, E. Research Diagnostic Criteria: Rationale and reliability. Archives of General Psychiatry, 35, 773 (1978).

Uhde, T.W., Bierer, L.M., and Post, R.M. Caffeine-induced escape from dexamethasone suppression. Archives of General Psychiatry, 42, 737 (1985).

Uhde, T.W., Boulenger, J.-P., Jimerson, D.C., and Post, R.M. Caffeine: Relationships to human anxiety, plasma MHPG, and cortisol. Psychopharmacology Bulletin, 20, 426 (1984).

Victor, B.S., Lubetsky, M., and Greden, J.F. Somatic manifestations of caffeinism. Journal of Clinical Psychiatry, 42, 185 (1981). 